Noname manuscript No.

(will be inserted by the editor)

\title{
Price volatility in the secondary market and bidders' heterogeneous behavior in Spanish Treasury auctions
}

\author{
Francisco Alvarez • Cristina Mazón
}

Received: date / Accepted: date

\begin{abstract}
We use multi-unit multi-bid common value auction models with private information to draw empirical implications on how bidding behavior in bond auctions is affected by secondary market price volatility, implications that we test using individual bidding data for 88 bond auctions held between 2003 and 2007 by the Spanish Treasury. The main novelty of the paper is that we analyze the effect of volatility in bidders heterogeneous behavior within an auction. We provide evidence that, as the theoretical models predict, the heterogeneity of bidders' bid shading increases with volatility, and that, on average across auctions, bid shading and bidders' profit also increase with volatility.
\end{abstract}

JEL codes: C13, D44, G28.

Keywords Multi-unit Auctions · Bidding Behavior · Treasury Auctions · Spanish Format · Intra-auction Heterogeneity

\section{Introduction}

This paper tries to contribute to a better understanding of bidding behavior in multi-unit multi-bid auctions, when the good being auctioned has a common value and bidders have private information about the value of the good. Despite the great amount of attention given to this type of auctions, both on theoretical and empirical literature, bidding behavior is not well understood. The reason is twofold. On the one hand, common value auction models with private information are quite complex, given that the private information of competing bidders is strategically relevant to bidders. As a consequence, the existing theoretical literature depends on strong simplifications of the economic environment, and even then, closed form solution equilibria are difficult to obtain. This implies that there is not a general characterization of individual bidder behavior. On the other hand, only recently information on individual bidding has been available to researchers to analyze empirically bidding behavior.

We consider one of the leading examples of multi-unit multi-bid auctions: Treasury auctions. Treasury bond auctions are usually considered to be common value auctions, with the value of the good common both across units and across bidders. ${ }^{1}$ This is a realistic assumption, given that there is an active secondary market after the auction, and bonds purchased at the auctions could be eventually resold on the secondary market, or directly to the bidders' clients. Furthermore, we want to investigate the fact that bidders bid differently from each other within an auction, what agrees with observed behavior in Treasury auctions. With otherwise symmetric bidders, to the best of our knowledge, this has been achieved in the theoretical literature only by assuming that bidders have private information about the common and unknown value of the good for sale. This assumption is reasonable for Treasury auctions, given

Francisco Alvarez

Fundamentos Análisis Económico II, Universidad Complutense Madrid

E-mail: fralvare@ccee.ucm.es

Cristina Mazón

Fundamentos Análisis Económico II, Universidad Complutense Madrid

E-mail: cmazon@ccee.ucm.es

\footnotetext{
${ }^{1}$ Structural models as Hortaçsu and McAdams (2010) and Kastl (2011) consider independent private values models, that they argue that are appropriate for short term bill auctions.
} 
that bidders are heterogeneous: both dealers and smaller investors bid in the auction. For dealers, as Armantier and Sbaï (2006) argue, the flow of pre-auction orders submitted by their clients, may explain why they form different forecasts about the future value of the bond.

In this paper, using individual bid data from Spanish Treasury auctions, we test empirically the implications of two common value models with private information with an analytical characterization of the equilibrium strategies. The models that we use are Alvarez and Mazón (2012), in what follows AM, for the uniform and discriminatory auction, and Wang and Zender (2002), in what follows WZ, for the uniform auction. ${ }^{2}$ Using models with private information is important to be able to draw predictions about how the heterogeneity of bidders' behavior in an auction changes with exogenous variables, a novelty in the empirical literature.

It should be noted that the models that we use assume either two indivisible units for sale and two bidders, AM, or a smooth demand, WZ, while in Treasury auctions there are more that two bidders, and they submit a collection of price-quantity pairs. Additionally, we use models for the uniform and the discriminatory formats, while the data that we use is for the Spanish format, a hybrid of both. Therefore, the theoretical demands from the models should be viewed only as an approximation. As in Keloharju et al (2005), we compute a number of summary statistics of individual demands and auction performance for the theoretical demands, that we compare with those that bidders actually submit.

Our central interest is to analyze how uncertainty about the value of the good, more specifically, the volatility prices in the secondary market of government debt, affects individual bidding behavior and, ultimately, the auction's outcome. The analysis of the effect of volatility on bidder's behavior within an auction is one of the main novelties of the paper.

We proceed as follows. First, we present some descriptive statistics on intra-auction heterogeneity, that is, differences in bid schedules across bidders within an auction, comparing them with inter-auction heterogeneity to give a relative measure. We conclude that for some variables that summarize bidding behavior, particularly bid spread and discount, ${ }^{3}$ intra-auction heterogeneity is important. From this observation, our target is twofold. First, to study empirically if intra-auction heterogeneity for variables characterizing bidding behavior and auction results can be explained by -are correlated to- secondary market volatility. We use linear regression analysis. Second, to link our results to the implications of theoretical common value auction models with private information. For both targets, we first construct a volatility time series, applying standard ARCH methodology to secondary market daily returns. We obtain volatilities ranging from $4 \%$ to $72 \%$, with a median of $23 \%$.

In order to obtain predictions from theoretical models, we proceed numerically. The models that we use, AM and WZ, obtain an explicit analytical expressions of the equilibrium bidding strategies, mapping each bidder's private information, her observed signal, into her submitted bid schedule or demand. We use sample statistics for the parameters of the models to obtain numerical values for the coefficients defining the equilibrium strategies for the models. For volatility, we consider a grid of values within the range of the estimated volatility. Then, for each value in that grid, with the values of all other parameters held constant, we simulate a large number of signals, and thus of bid schedules, and obtain cross-simulation statistics on variables defining the bid schedules. Particularly, the cross-simulation standard deviation of a variable defining bidders' behavior, for a given value of volatility in the grid, is a measure of intra-auction heterogeneity when all bidders play the same -in fact the unique- equilibrium strategy. As we consider different values of volatility along the grid, we generate theoretical predictions on how intra-auction heterogeneity changes with volatility in the theoretical models under consideration.

Our main contributions are as follows. Both theoretical models predict that, on average, bidders increase bid spread as volatility increases, hedging the winner's curse. ${ }^{4}$ While the AM's model predicts

\footnotetext{
${ }^{2}$ We use their examples for their more general models, presented in Subsection 4.2 for AM and Subsection 4.4 for WZ.

${ }^{3}$ Bid spread is the difference between the highest and the lowest bid. Bid shading or discount is the difference between the expected value of the good at the time of bidding and the average bid price.

${ }^{4}$ The winner's curse or champion's plague in multi-unit auctions, arise in common value models with private information, since the bidder's conditional expected value is decreasing in the number of units that he wins. Hence bidders shade their bids to adjust ex ante. This expression is from Gordy (1999).
} 
that, on average, bidders increase discount as volatility increases, the WZ's model for the uniform auction predicts that discount decreases with volatility. Both models predict that, on average, bidders' profit per unit increases with volatility. Additionally, intra-auction heterogeneity also increases with volatility: at least for low values of volatility, both models predict that bid spread, bids and discount are more heterogeneous among bidders in a given auction as volatility increases. These predictions are in part consistent with the data. We provide evidence that in Spanish Treasury auctions, on average, bidders increase discount as volatility increases, as predicted by the AM's model. As a result, average bidders' profit also increases with volatility. More importantly, we provide evidence that bidders' heterogeneity within an auction increases with volatility: the standard deviation of the high bid increases with volatility, as predicted by both the AM's and the WZ's models, and the standard deviation of discount also increases with volatility, as predicted by the WZ's model and for the AM's model for low values of volatility. These are new results in the literature, since most previous empirical studies assuming common value, use models without private information and do not consider intra-action heterogeneity.

There are a number of studies using bidder-level data to analyze how bidding behavior responds to volatility in Treasury auctions for different European countries, both for uniform and discriminatory auctions. Most of them use common value models. Keloharju et al (2005) investigates how bidder behavior and bid shading responds to secondary market volatility for uniform Finnish Treasury auctions. They test the empirical predictions of multi-unit common value models without private information, and therefore they are not able to obtain implications on bidders' heterogeneous behavior in a given auction. They find that as volatility increases, bidders increase bid shading, decrease quantity demanded and increase the dispersion of their bids, suggesting that bidders adjust for the winner's curse. Similar results for discriminatory auctions are reported by Nyborg et al (2002) for Swedish Treasury auctions, by Elsinger and Zulehner (2007) for Austrian Treasury auctions, and by Rocholl (2006) for German Treasury auctions; he also documents the use of seller's discretion and its influence on bidding strategies. Gordy (1999), presents evidence that bidders increase the number of bids ans the dispersion of their bids with uncertainty, for Portuguese discriminatory Treasury bill auctions. Finally, Hortaçsu (2002) uses an independent private value model to analyze bidding behavior for discriminatory Turkish bill auctions. He analytically characterizes the equilibria in a two bidder model, to draw empirical implications. He finds that bid shading increases with volatility and the number of bidders, and decreases with the uncertainty in supply.

Other studies using individual bidder-level data use a structural approach to estimate bidders' valuations, ${ }^{5}$ and conduct counterfactual experiments to compare the efficiency and revenue generating properties of alternative auction mechanisms. Assuming independent private values, Hortaçsu and McAdams (2010) and Kang and Puller (2008) follow Wilson's (1979) share auction approach, while Kastl (2011) uses a discrete model. Fevrier and Visser (2002) follow Wilson's (1979) common value model to pursue an estimation strategy analogous to the private values case considered in the previous papers. Finally, Armantier and Sbaï (2006) and Armantier and Lafhel (2009) generalize WZ's model, and rely on numerical techniques to approximate the equilibrium. Note that these structural models either characterize necessary conditions for equilibrium, without providing an explicit equilibrium solution, or approximate the equilibrium numerically.

The paper is organized as follows. Section 2 describes the institutional background and the data used, Section 3 presents descriptive statistics of bidder's demands and auction results, Section 4 presents the theoretical models and their empirical implications, and Section 5 presents the empirical analysis of bidder's behavior and auction results. Finally, Section 6 concludes.

\section{Institutional Background and Data}

The Spanish Treasury uses a unique auction format to sell government debt, the Spanish auction. The Spanish auction combines elements of the uniform format with elements of the discriminatory format. In the uniform, discriminatory and Spanish auctions bidders submit multiple price-quantity pairs as their bids. The bids are classified by descending order of price and the Treasury decides, on the basis of the last bid admitted, the stop-out price. All bids at or above the stop-out price are accepted, unless quantity

\footnotetext{
${ }^{5}$ See Hortaçsu (2011) for a survey on structural models.
} 
demanded exceeds quantity supplied at the stop-out price. In that case a pro rata formula is used, affecting only bids made at the stop-out price. The prices paid depend on the auction format. While in the uniform auction bidders pay the stop-out price for every unit won, in the discriminatory auction bidders pay their bid for each unit won, and in the Spanish auction, bidders pay their bid for bids between the weighted average price of winning bids and the stop-out price, and the weighted average price for bids higher than the weighted average price.

The Spanish Treasury issues Bonos y Obligaciones del Estado, Treasury bonds, securities with maturities above two years, paying annual coupons. Bids are either competitive, specifying both the quantity desired and the price, or non-competitive, specifying only the quantity desired; non-competitive bids are accepted in full and pay the auction's weighted average price. Any investor can submit bids in the auctions, although most bids are made by Market Makers, a group of financial institutions with given obligations and rights, whose purpose is to stimulate the liquidity of the secondary market in Public Debt. In the period considered, there were twenty Market Makers for bonds, that bought, on average, $96.7 \%$ of issued bonds using mainly competitive bids. In this paper we analyze the behavior of Market Makers, and refer to them as the bidders. ${ }^{6}$

The Treasury may sell new securities or additional amounts of securities that are already traded on the secondary market, what is known as reopenings or issuance by tranches. Each asset is identified by an ISIN code.

\subsection{Auction Data}

For this study we use a data set supplied by the Spanish Treasury, which contains all the bids made by Market Makers, plus aggregate demand at each price for all other bidders, in 88 bond auctions held between January 2003 and December 2007, with 82 reopenings and only 6 new securities. In the data, there are 25 auctions for 3 year bonds, 18 for 5 year, 23 for 10 year, 9 for 15 year and 13 for 30 year bonds. For each auction the data includes an anonymous identification code of the bidder, quantity and price bids, quantity accepted, and price paid, if accepted, for each quantity bid.

Table (1) reports summary statistics describing the auctions in our sample. In the Table, the columns include the mean, standard deviation, minimum and maximum value, and number of observations of the corresponding variable. On average, each bidder presents 2.53 competitive bids, ${ }^{7}$ and demands a total of 138 millions of Euros and 55 millions of Euros per bid. The average bid price, as a percentage of face value, is 103.6, with a large standard deviation due to the fact that bonds have a wide maturity range. The average of auction size is 1334 millions of Euros. Finally, the percentage of total demand awarded to non competitive bids is, on average, $3.32 \%$.

Table 1: Summary of auction statistics

\begin{tabular}{lrrrrr}
\hline & Mean & Std & Min & Max & Num. obs. \\
\hline Bids per Bidder & 2.53 & 0.38 & 1.42 & 3.60 & 88 \\
Demand per Bidder & 138.38 & 60.56 & 40.95 & 351.50 & 88 \\
Mean Bid Quantity & 54.77 & 20.13 & 14.83 & 110.04 & 86 \\
Mean Bid Price & 103.60 & 5.96 & 92.81 & 121.10 & 88 \\
Auction Size & 1334.45 & 695.16 & 370.52 & 3789.23 & 88 \\
\% Non Competitive Demand & 3.32 & 3.83 & 0.05 & 13.63 & 88 \\
\hline
\end{tabular}

\footnotetext{
${ }^{6}$ See Arnone and Iden (2003) for a comprehensive analysis of the role of Market Makers in the management of government debt in the Euro zone. See Appendix A for some additional details on the institutional background.

${ }^{7}$ The maximum number of bids in a demand is 11 bids.
} 


\subsection{Secondary Market Data}

We use two sets of secondary market data. We use data from MTS, one of Europe's leading electronic fixed income trading markets providing data on secondary market transactions, to estimate the secondary market price at the time of the auction, and data from the Bank of Spain to estimate the secondary price after the auction and to construct a volatility time series.

\subsubsection{Data from MTS}

MTS is the electronic platform on the first-tier trade $^{8}$ with the highest volume of trading for Spanish government securities though the sample, ${ }^{9}$ and provides data for Fills and Best Proposals. Fills contain information on trades carried out by MTS for all Spanish Treasury bonds. ${ }^{10}$ Best Proposals includes the best three quotes that occurred throughout each day. We have data for Fills from April 2003 to December 2007, and for Best Proposals from January 2005 to December 2007.

\subsubsection{Data from the Bank of Spain}

Data from the Bank of Spain include all spot transactions in single operations in Mercado de Deuda Publica Anotada. ${ }^{11}$ For each issue and trading day, the Bank of Spain publishes information on the number of transactions, the nominal and effective traded volume, and the maximum, minimum and average price and yield at which trade takes place. The data includes both operations between market members and between market members and third parties.

Over the period from January 2003 to December 2007 there were 150,944 bond transactions. The total nominal traded was 1,709 millions of Euros, with average nominal traded per day of 1.33 millions of Euros. The average number of operations per day was 118 .

\subsection{Volatility Estimation}

We use secondary market data from the Bank of Spain to construct a volatility time series for bonds. We estimate volatility as an $\mathrm{ARCH}(1)$ model of returns. There are 16 ISIN codes in our sample, and we estimate a different model for each of them.

Following Keloharju et al (2005), we assume that bond returns follow a random walk with constant drift $a$,

$$
\frac{P_{t}-P_{t-1}+A}{P_{t-1}}=a+e_{t}
$$

where $P_{t}$ is the bond price at time $t$ and $A$ is the one-day accrued interest for a coupon.

On average, daily volatility is $0.22 \%$, somewhat lower to the estimates that Nyborg et al (2002) report for Swedish bonds, 0.28\% over the period 1990 to 1994 and Keloharju et al (2005) report for Finnish bonds, 0.36\%, over the period 1992 to 1999. Both of them estimate ARCH(2) models, pooling cross-section and time-series data; that is, they estimate one model for all bonds, while we estimate 16 models, one for each ISIN code in our sample. ${ }^{12}$

\footnotetext{
${ }^{8}$ The first tier or blind market is the core of the public debt market, reserved for market members or account holders; trades are conducted without the knowledge of the counter party identity and transaction size is a minimum of 5 million Euros.

${ }^{9}$ Except for 2006.

${ }^{10}$ It includes the date and time of the trade, the market on which the trade occurs, ISIN code, if the dealer is buying or selling, the price and the size of the trade, whether the originating order was completely filled or only partially filled, and the profile of the aggressor member on that market.

${ }^{11}$ http://www.bde.es/webbde/es/secciones/informes/banota/series.html, files CONTYYYY.TXT.

${ }^{12}$ See Appendix B for additional details on the volatility estimation.
} 


\section{Descriptive Statistics of Bidders' Behavior and Auction Results}

In this section we present descriptive statistics to illustrate the heterogeneity of bidders' behavior and auction results. We consider differences across auctions (inter-auction heterogeneity of bidder's behavior and auction results), and differences in an auction (intra-auction heterogeneity of bidder's behavior and auction results).

We look at four measures of bidders' behavior: bid spread and discount, explained by high and low bid; and one measure of auction performance: bidders' profit per unit. Tables (2) and (3) provide summary statistics for those variables. For all the variables, we first calculate its value for each bidder at a given auction, and then compute the average and the standard deviation of that variable for each auction.

Consider first Table (2), that reports the mean across auctions of the variables' per auction average, to capture inter-auction differences. As in Table (1), the columns include the mean, standard deviation, minimum and maximum value, and number of observations. The extent to which bidders disperse their bids is measured by bid spread, defined as the difference between the highest and lowest bid for each individual demand. On average, bid spread is equal to $0.07,70$ cents for a bond with a face value of 1000 Euros. The average high and low bid are equal to 103.63 and 103.56, respectively.

Discount or bid shading is a measure of how much bidders' bids are shaded relative to the value of the good. It is defined as the difference between the secondary market price and the quantity weighted average bid price. For the secondary market price, we use the quantity weighted average price of the transactions taking place during the hour previous to the auction time. ${ }^{13}$ We find evidence that bidders shade their bids: the average across auction of the mean discount is 0.025 , and it is significantly different than zero at the usual level ( $5 \%$ or lower, for the rest of the paper). However, discounts are much lower that those reported for other countries, and negative, on average, for 3 and 5 year bonds. ${ }^{14}$

Table 2: Summary statistics for bidder' behavior and auction results

\begin{tabular}{lrrrrr}
\hline & Mean & Std & Min & Max & Num. obs. \\
\hline Bid Spread & 0.07 & 0.07 & 0.01 & 0.33 & 88 \\
High Bid & 103.63 & 5.97 & 92.83 & 121.16 & 88 \\
Low Bid & 103.56 & 5.94 & 92.80 & 121.05 & 88 \\
Discount & 0.025 & 0.078 & -0.08 & 0.279 & 60 \\
Profit & 0.012 & 0.344 & -0.895 & 1.083 & 79 \\
\hline
\end{tabular}

Finally, Table (2) presents the average of bidders' profit per unit or underpricing, a measure of auction performance. It measures how the auction's selling price is underpriced relatively to the secondary market, and it is defined as the difference between the secondary market price of the underlying security the day after the auction, and the quantity weighted average price paid on winning bids. For the secondary market price we use the quantity weighted price of the day after the auction, adjusted to the settlement date of the auction, using data from the Bank of Spain. ${ }^{15}$ The average across auctions of the

\footnotetext{
${ }^{13}$ Fills from MTS. We also used the price of the transaction closest to the auction time, on the interval [-10 minutes, +10 minutes] around the auction time. We had data on that interval for 50 of the 88 bond auctions on the data, and the average discount is not significantly different from 0.

${ }^{14}$ For discriminatory auctions, Rocholl (2006) reports for Germany a discount that increases with duration, ranging from 0.076 to 0.149 , while Nyborg et al (2002) report for Swedish bonds with duration between five and eight years discounts that range from 0.252 to 0.478 . For uniform auctions Keloharju et al (2005) reports for Finnish Treasury bond auctions a positive and significant discount of 0.081 . The negativity of discount could be explained either by overbidding or by the $V$-effect. There is overbidding when bidders bid above the market price at the time of the auction, a problem of the primary dealer structure, as documented by Dunne et al (2010). The $V$-effect, documented by Pacini (2006) for Treasury auctions in Italy and France, consist on secondary market prices on the auction date that move with a $V$-shape, with the $V$ lower corner at the auction time.

${ }^{15}$ To adjust to the settlement date, we first calculate the internal rate of return for the bond, and then we use it to obtain the price as the sum of the present value of the expected cash flow (where the cash flow is the annual coupon plus the maturity value.). We also calculated profit with the same price that we use when calculating discount, the price of the transaction closest to the auction time on the interval [-10 minutes, +10 minutes]. However, we have data only for 50
} 
mean profit is not significantly different from 0 at the standard confidence levels. This could indicate that the seller chooses the auction price close to the market price, as is the case for the German Treasury auctions, as reported by Rocholl (2006), who finds negative although statistically insignificant average maximum profit for most auctions at bidding time. ${ }^{16}$ It is also in line with the results of Gordy (1999) for Portuguese Treasury bill auctions, and Pacini (2006), who reports what he denotes as overpricing, auction prices above the secondary market price at the time of the auction and during the auction day, for Treasury auctions in the European Economic Union, including the Spanish Treasury, in 2004. It contrasts with the positive and significant profit for other countries including the United Sates, as reported by Goldreich (2007) and Finland, as reported by Keloharju et al (2005).

We want to illustrate if intra-auction heterogeneity is relevant in the Spanish Treasury auctions. For that, we compare the average of the standard deviation within auctions, to capture intra-auction heterogeneity, with the standard deviation of each variable average across auctions, (the second column in the previous Table), to capture inter-auction heterogeneity. Table (3) presents such information, where we have added information for some variables included on Table (1). The first column is the average across auctions of the standard deviation of each variable within an auction; the second column is the standard deviation of each variable's average across auction. What we observe is that there is more heterogeneity for bid spread intra-auction, with an average standard deviation of 0.13 , than inter-auction, with an standard deviation of 0.07 . This is also the case for discount, when we consider information for different bond types; for all bond types except 15 year bonds, the average of the within auction standard deviation is greater than the standard deviation of the intra-auction average: there is more intra-auction than inter-auction heterogeneity for discount. Bids per bidder and mean bid quantity also have higher heterogeneity intra-auction, with an average standard deviation of 1.22 and 40.32, respectively, than across auctions, with an average standard deviation of 0.38 and 20.80 , respectively.

Table 3: Summary variation intra vs inter-auction

\begin{tabular}{lcc}
\hline & Avg of Intra-auction Std & Std of Intra-auction Avg \\
\hline Bid Spread & 0.13 & 0.07 \\
High Bid & 0.07 & 5.97 \\
Low Bid & 0.13 & 5.94 \\
Discount & 0.06 & 0.08 \\
Profit & 0.01 & 0.34 \\
Bids per Bidder & 1.22 & 0.38 \\
Mean Bid Price & 0.06 & 5.96 \\
Mean Bid Quantity & 40.32 & 20.80 \\
\hline
\end{tabular}

As expected, there is lower heterogeneity intra-auction than inter-auction for high and low bid, given that there is data for bonds with different maturity, what should be reflected in the bid prices. This is also the case for mean bid price, for which the intra-auction heterogeneity is extremely small, with an average intra-auction standard deviation of only 0.06, less than half of the standard deviation for bid spread. For bidders' profit, it is also the case that there is lower heterogeneity intra-auction than inter-auction. The average standard deviation within auction is only 0.01 , implying that profit per unit in an auction are quite similar across bidders; this could be explained by the fact that in the Spanish auction the highest price paid is the weighted price of winning bids, and the tail, defined as the difference between the maximum and the minimum price paid at the auction, is only 0.038 .

bond in that interval, and additionally, average profit are negative, on average, and significantly different from zero. As we argued on Footnote 14, Market Makers may lower their bid and ask quotes around the time of the auction, so we consider that transactions on the day after the auction are a more reliable measure of profit.

${ }^{16}$ Maximum profit because although Treasury auctions in Germany are discriminatory, he reports the difference between the market price of the security and the auction clearing price, lower than the quantity weighted price of winning bids. 


\section{Theory of Bidder Behavior and Empirical Implications}

The central question of this paper is to analyze how -and why- secondary market volatility affects bidding behavior and auction results in bond Treasury auctions. In this section we address the why question, obtaining empirical implications from theoretical models. As we argued in the Introduction, we need multi-unit, multi-bid, common value models, in which bidders have private information about the value of the good.

Additionally, in order to easily derive predictions on the effect of volatility on bidding behavior and auction results, we want models that provide an explicit solution for the equilibrium strategies. Some models, as WZ, present general characterization of the equilibria, with explicit solutions that are generally difficult to obtain; some others, as Armantier and Sbaï (2006), Hortaçsu and McAdams (2010) and Kastl (2011), that follow a structural approach, obtain necessary conditions for equilibrium, without providing an explicit solution for the equilibrium strategies. ${ }^{17}$ Therefore, none of those characterizations allows for a straightforward derivation of predictions on the effect of volatility on bidding behavior.

There are two papers that provide examples of their more general models with explicit solutions, that we use to obtain empirical predictions: AM, for the uniform and discriminatory auction, and WZ for the uniform auction. ${ }^{18}$ Both models are quite different. While AM assume that the good for sale is indivisible and quantities are discrete, WZ follow Wilson's share auction approach. They also share some common elements. Both models build on the mineral right model. Let $\tilde{v}$ denote the value of the good, unknown at the time of bidding. Prior to bidding, bidder $i$ receives a private signal $\tilde{s}_{i}$, that is equal to the common value of the good, $\tilde{v}$, plus an idiosyncratic noise component $\tilde{\varepsilon}_{i}$,

$$
\tilde{s}_{i}=\tilde{v}+\tilde{\varepsilon}_{i}
$$

where the variables on the right hand side of (1) are globally independent.

Both models also have in common that they make distributional assumptions in the fundamental random variables of the model that imply that the expected value of the good, conditional on the signal observation, $E\left\{\tilde{v} \mid s_{i}\right\}$, is linear in $s_{i}$. More specifically,

$$
E\left\{\tilde{v} \mid s_{i}\right\}=E\{\tilde{v}\}+\lambda\left(s_{i}-E\left\{\tilde{s}_{i}\right\}\right)
$$

where $\lambda:=\frac{\operatorname{Cov}\left(\tilde{v}, \tilde{\varepsilon}_{i}\right)}{\operatorname{Var}\left(\tilde{\varepsilon}_{i}\right)}=\frac{\sigma_{v}^{2}}{\sigma_{v}^{2}+\sigma_{\varepsilon}^{2}}, \sigma_{v}^{2}$ and $\sigma_{\varepsilon}^{2}$ are, respectively, the variance of the value of the good and of the noise component, and the latter equality follows from the independence assumption between $\tilde{v}$ and $\tilde{\varepsilon}_{i}$, stated above.

Next, we present briefly the two models that we use, and the empirical implications that we obtain.

\subsection{An indivisible good and discrete quantities model}

In AM, there are two identical and indivisible units for sale, and two bidders. Price is a continuous variable. A strategy is a pair of functions defined from the signals' support to the set of prices, $\left(p_{h}(),. p_{l}().\right)$, such that a bidder that follows that strategy bids the pair of prices $\left(p_{h}\left(s_{i}\right), p_{l}\left(s_{i}\right)\right)$ when she observes signal $s_{i} \cdot{ }^{19}$

The value of the good, $\tilde{v}$, is assumed to be a finite sum of i.i.d. uniformly distributed variables, and the idiosyncratic error term, $\tilde{\varepsilon}_{i}$, is assumed to be uniformly distributed. AM characterize the symmetric Bayesian Nash equilibrium, both for the uniform and the discriminatory formats. They show that for

\footnotetext{
${ }^{17}$ Armantier and Sbaï (2006) rely on numerical techniques to approximate the Bayesian Nash equilibrium in a common value model with private information, and then estimate the structural parameters of the model; their approach is beyond the scope of this paper.

${ }^{18}$ Subsections 4.2 for AM and Subsection 4.4 for WZ.

${ }^{19}$ Without loss of generality, $p_{h}\left(s_{i}\right) \geq p_{l}\left(s_{i}\right)$ for all $s_{i}$, so that $p_{h}\left(s_{i}\right)$ and $p_{l}\left(s_{i}\right)$ denote the high and low bid, respectively.
} 
both formats there exist equilibria conformed by strategies in which prices are linear in the signal. The unique linear equilibrium for the discriminatory auction is

$$
p^{d}\left(s_{i}\right)=\underline{v}+\frac{\lambda}{2-\lambda}\left(s_{i}-\underline{s}\right)
$$

while the unique linear equilibrium for the uniform auction is

$$
p_{h}^{u}\left(s_{i}\right)=\underline{v}+\frac{2 \lambda}{3-\lambda}\left(s_{i}-\underline{s}\right) ; \quad p_{l}^{u}\left(s_{i}\right)=\underline{v}+\frac{\lambda(1+\lambda)}{3-\lambda}\left(s_{i}-\underline{s}\right)
$$

where $\underline{v}$ and $\underline{s}$ are the infimum of the supports of $\tilde{v}$ and $\tilde{s_{i}}$, respectively, and $\lambda$ is as defined above, $\lambda:=\frac{\sigma_{v}^{2}}{\sigma_{v}^{2}+\sigma_{\varepsilon}^{2}}$.

The relative position of the equilibrium strategies of both formats is as represented in Figure 1, that also represents the expected value of the good conditional on the observed signal, $E\left\{v \mid s_{i}\right\}$. In the Figure, $\left(p_{h}^{u}(),. p_{l}^{u}().\right)$ is the equilibrium strategy for the uniform format, and $\left(p_{h}^{d}()=.p_{l}^{d}().\right)$ is the equilibrium strategy for the discriminatory auction, in which bidders bid the same price for both units.

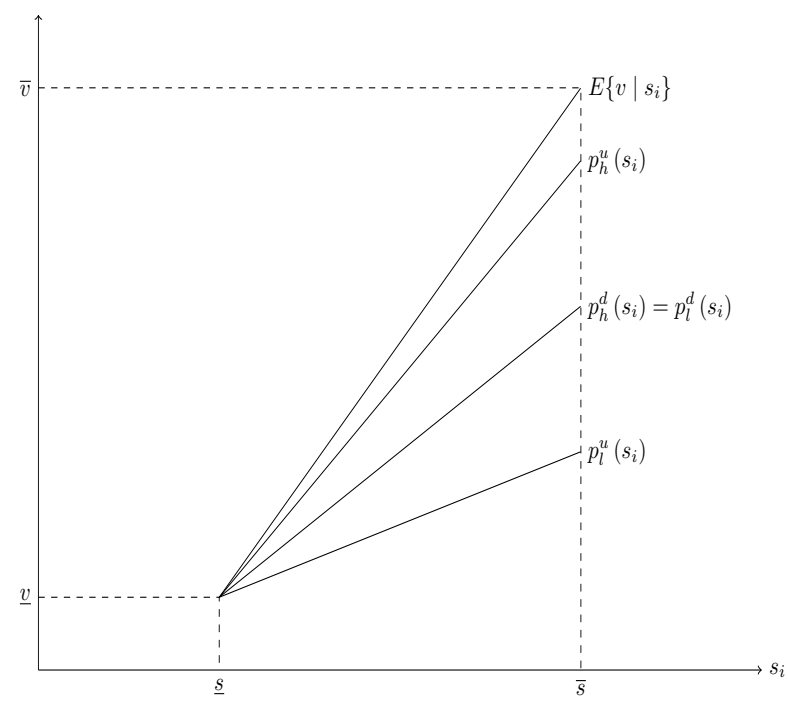

Fig. 1: Relative position of equilibrium strategies in the AM's model. The superscripts $d$ and $u$ stand for discriminatory and uniform format, respectively. The marginal supports of the signal and the value of the good are $[\underline{s}, \bar{s}]$ and $[\underline{v}, \bar{v}], \operatorname{respectively.~}$

In both the uniform and the discriminatory formats bid prices are increasing with the observed signal. In the uniform auction, bidders bid different prices for both units for all signals but the lowest, even if they value them equally, and an increase in the signal observation increases the high bid more than the low one. In the discriminatory auction, in contrast, bidders bid the same price for both units. The relative position of equilibrium bid schedules is such that for all signal observations but the lowest, the high bid in the uniform auction is higher than the bid for both units in the discriminatory auction, which in turn is higher than the low bid in the uniform auction. For both auction formats, bidders shade their bids with respect to the expected value of the good conditional on the signal observation, for all signals but the lowest.

Note that the AM's model is for the uniform and discriminatory auctions, but our data is for the Spanish auction. Our guess is that bid spread would be lower for the Spanish than for the uniform auction, but higher than for the discriminatory auction, given that it is a hybrid of both formats. ${ }^{20}$

\footnotetext{
${ }^{20}$ With respect to the discriminatory auction, in Alvarez and Mazón (2007) we find that bid spread is larger for the Spanish than for the discriminator auction, both because the high bid is greater and the low bid is lower in the Spanish than in the discriminatory auction. We find the equilibria numerically, and there are parameter values for which equilibria do not exist or for which there are multiple equilibria, which limits the predictive capacity of the model. In contrast, in AM there is a unique equilibrium given the assumptions of the model.
} 
From equations (3) and (4), note that the equilibrium strategies are completely characterized by three parameters: the mean and variance of the value of the good, $E\{\tilde{v}\}$ and $\sigma_{v}^{2}$, and the variance of the error term, $\sigma_{\varepsilon}^{2}$. Given values for $E\{\tilde{v}\}$ and $\sigma_{v}^{2}$, we can obtain the numerical values for the coefficients defining the equilibrium strategies. ${ }^{21}$

4.2 A divisible good, continuous bid functions and uncertain supply model

WZ follow Wilson's share auction approach, in which the good is perfectly divisible, both quantities and prices are continuous variables, and bids are strictly downward-sloping demand functions. There are $N>2$ risk averse competitive bidders, that maximize the expected value of a CARA utility function, with common risk aversion parameter $\rho$. Bidders compete for an uncertain quantity $1-\tilde{z}$, where $\tilde{z}$ is a random variable that accounts for non-competitive demand, with variance $\sigma_{z}^{2}$. They assume that $\tilde{v}, \tilde{\varepsilon}_{i}$ and $\tilde{z}$ are normally distributed, the last two with zero mean. They consider equilibria in bid schedules that are additively separable in the price and the bidder's private signal, and consider the uniform auction.

An equilibrium strategy in their model for the uniform auction is

$$
x_{i}\left(p, s_{i}\right)=\mu+\beta s_{i}-\gamma p
$$

where $x_{i}\left(p, s_{i}\right)$ is the quantity demanded by bidder $i$ at price $p$ when she observes signal $s_{i}$, and the coefficients $(\mu, \beta, \gamma)$ are defined by the parameters of the model. Equation (5) indicates that bidder $i$ submits a demand function that is linear in the signal observation and in the price, and such that the slope of the bid schedule does not depend on the signal, i.e., different signals affect only the demand's intercept.

Given values for the parameters $\left(N, \rho, \sigma_{z}^{2}, E\{\tilde{v}\}, \sigma_{v}^{2}, \sigma_{\varepsilon}^{2}\right)$, we can obtain numerical values for the coefficients $(\mu, \beta, \gamma)$ in equation (5), which defines the equilibrium bidding strategy played by all bidders.

\subsection{Empirical Implications}

In this Subsection we derive testable implications from the models presented above. We consider the variables for which we presented summary statistics in Section 3: bid spread, high and low bid, discount, and bidders' profit per unit. Next, we define the variables for the theoretical models.

Bid spread, the difference between the highest and the lowest bid price in an individual demand, is equal to zero in the discriminatory auction in the AM's model, since bidders bid the same price for both units. For the uniform auction is defined, respectively, for AM and WZ as

$$
B S_{A M}\left(s_{i}\right)^{U}:=p_{h}\left(s_{i}\right)-p_{l}\left(s_{i}\right) ; \quad B S_{W Z}\left(s_{i}\right)^{U}:=p_{\max }\left(s_{i}\right)
$$

where $p_{\max }\left(s_{i}\right)$ is the solution in $p$ to $x_{i}\left(p, s_{i}\right)=0$, i.e., the demand intercept.

Discount is defined as the difference between the expected value of the good, conditional on the signal observation, and the weighted average price of their bids. For the AM and WZ's models we calculate discount, respectively, as

$$
\begin{array}{r}
D_{A M}\left(s_{i}\right):=E\left\{\tilde{v} \mid s_{i}\right\}-\frac{1}{2}\left(p_{h}\left(s_{i}\right)+p_{l}\left(s_{i}\right)\right) \\
D_{W Z}\left(s_{i}\right):=E\left\{\tilde{v} \mid s_{i}\right\}-\int_{0}^{p_{\max }\left(s_{i}\right)} p \frac{x_{i}\left(p, s_{i}\right)}{X\left(s_{i}\right)} d p
\end{array}
$$

where $X\left(s_{i}\right):=\int_{0}^{p_{\max }\left(s_{i}\right)} x_{i}\left(p, s_{i}\right) d p$ is the total quantity demanded by bidder $i$. Note that $\frac{x_{i}\left(p, s_{i}\right)}{X\left(s_{i}\right)}$ is the fraction of quantity demanded at price $p$ over total quantity demanded, so that the integral in the definition of $D_{W Z}($.$) is the weighted average price.$

Finally, bidders' profit per unit is defined as the difference between the expected value of the good and the stop-out price for the uniform auction, both in the AM and WZ's models. For the AM's discriminatory auction, given that bidders bid the same price for both units, it is equal to the expected value of

${ }^{21}$ In the model, given a value for $\sigma_{v}^{2}$, the value for $\sigma_{\varepsilon}^{2}$ is such that $\frac{\sigma_{v}^{2}}{\sigma_{\varepsilon}^{2}}$ is an integer greater than 1. 
the good minus the winning bid. Note that bidder's profit per unit is equal for all bidder's in a uniform auction, and also for the discriminatory auction in the AM's model.

We want to analyze the effect of changes on the the variance of the value of the good on the average and the standard deviation of the variables defining bidders' behavior and auction results. In neither of these two models it is possible to obtain the effect analytically, so that we evaluate the effect numerically.

We proceed as follows. We use sample statistics for the parameters of the models to obtain numerical values for the coefficients defining the equilibrium strategies. For volatility, we consider a grid of values within the range of estimated volatility. For each value in that grid, with the values for all other parameters held constant, given the distributional assumptions of each model, we simulate 1000 signals. The equilibrium strategies map each of those realizations into a bid schedule (one price in AM's discriminatory auction, a pair of prices in AM's uniform auction, and a linear demand in WZ's uniform auction), that is characterized by bid spread, discount, high bid and low bid. The cross-simulation standard deviation of a variable defining bidders' behavior, for a given value of volatility in the grid, measures intra-auction heterogeneity for a given value of volatility. As we consider different values of volatility along the grid, we generate theoretical predictions on how intra-auction heterogeneity changes with volatility in the theoretical models under consideration. While the previous variables characterize bidders' demands, bidders' profit per unit characterizes an equilibrium. We consider for each model 100 auctions, computing the equilibria given the number of bidders in each model, and proceed as for the variables defining bidders' behavior.

To obtain the values of the coefficients defining the bid schedules in the AM model, as mentioned above, we need values for parameters $\left(E\{\tilde{v}\}, \sigma_{v}^{2}, \sigma_{\varepsilon}^{2}\right)$. We set $E\{\tilde{v}\}$ equal to 101.73 , the average price of the secondary market in our sample, and take values for $\sigma_{v}^{2}$ in the interval $(4.38 \%, 72.04 \%)$, the range of the estimated secondary market volatility on auction days. Finally, we take the values of $\sigma_{\varepsilon}^{2}$ to fulfill the assumptions of the model. ${ }^{22}$ In the WZ's model, the parameter values $\left(N, \rho, \sigma_{z}^{2}, E\{\tilde{v}\}, \sigma_{v}^{2}, \sigma_{\varepsilon}^{2}\right)$ define the coefficients of the equilibrium strategies. We take $N$ equal to 20 , since that is the number of competitive bidders in our data, $\rho$ equal to 0 , so that bidders are risk neutral and the results are directly comparable with $\mathrm{AM},{ }^{23} \sigma_{z}^{2}$ equal to the variance of the ratio of noncompetitive quantity demanded to auction size in our data, and $E\{\tilde{v}\}, \sigma_{v}^{2}$ and $\sigma_{\varepsilon}^{2}$ as in AM. The association between parameters of the models and sample statistics is summarize in Table (4), in which a $\checkmark$ in the columns AM or WZ indicates that the corresponding parameter is used in that particular model.

Table 4: Parameter values and sample statistic

\begin{tabular}{|c|c|c|c|}
\hline & & $\mathrm{AM}$ & WZ \\
\hline$E\{\tilde{v}\}=101.73$ & Average secondary market price & $\checkmark$ & $\sqrt{ }$ \\
\hline$N=20$ & Number of bidders in Spanish bond auctions & & $\checkmark$ \\
\hline$\rho=0$ & & & $\checkmark$ \\
\hline$\sigma_{z}^{2}=0.14 \%$ & Inter-auction variance of non competitive demand/auction size & & $\checkmark$ \\
\hline$\sigma_{v}^{2} \in(4.38 \%, 72.04 \%)$ & Range of estimated secondary market volatility on auction dates & $\sqrt{ }$ & 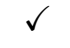 \\
\hline$\sigma_{\varepsilon}^{2}$ such that $\frac{\sigma_{v}^{2}}{\sigma_{\varepsilon}^{2}} \in \mathbb{N}_{+}$ & Restriction necessary for AM & $\checkmark$ & $\checkmark$ \\
\hline
\end{tabular}

We obtain the average and the standard deviation of the variables defining bidders' behavior as the corresponding sample statistic from the realizations of $\tilde{s}_{i}$, and compute the equilibrium to obtain bidders' profit and calculate its average across auctions. This procedure associates values for the average and the standard deviation of the defined variables to a given vector of parameter values. Thus, by varying $\sigma_{v}^{2}$, keeping all other parameters constant, we generate empirical implications from AM and WZ's models on how volatility affects bidding behavior and auction results.

We present the results of the simulations graphically, the empirical implications of both models for the uniform auction on bidding behavior on Figure (2), and on bidder's profit on Figure (3). In the Figures,

${ }^{22}$ Remember that $\frac{\sigma_{v}^{2}}{\sigma_{\varepsilon}^{2}}$ is an integer greater than 1.

${ }^{23}$ Results do not vary when we consider risk averse bidders, taking positive values for $\rho$. 
$\sigma_{v}^{2}$ is represented in the horizontal axis, and the graphs show how the average or standard deviation of the corresponding variable change as volatility increases. In each panel, the different lines correspond to different values of $\sigma_{\varepsilon}^{2}$, with $\sigma_{\varepsilon}^{2}$ increasing as we shift from red (and narrow) to green (and wide). ${ }^{24}$

Consider first the empirical implications of the AM's model for the uniform auction on bidder's behavior. Panels (a), (b) and (c) on Figure (2) show how average bid spread, high and low bid change with volatility. Average bid spread is positively correlated with volatility: on average, bidders increase bid spread as volatility increases. As the volatility of the value of the good increases, the greater is the potential for the winner's curse and bidders respond increasing the dispersion of their bids. Average high and low bid are negatively correlated with volatility. Therefore, the AM's model for the uniform format predicts that bidders decrease both their high and low bid, increasing bid spread, as volatility increases. Given that it can be proved analytically that in equilibrium discount is equal to a constant times bid spread, we conclude that discount is also positively correlated with volatility: the AM's model predicts that average bid shading increases with volatility.

Panels (d), (e) and (f) illustrate how the standard deviation of bid spread, high bid and low bid within an auction vary with volatility in the AM's uniform auction. The model predicts that the relation of the standard deviation of bid spread, and therefore of discount, and volatility, is not monotonous: both increase with volatility for low values of $\sigma_{v}^{2}$, and decrease for large values of $\sigma_{v}^{2}$. On the other hand, the standard deviation of the high and the low bid are positively correlated with volatility: the model predicts that intra-auction heterogeneity on the high and the low bid increases with volatility.

Consider next the empirical implications of the WZ's model for the uniform auction on bidder's behavior. Panels (g) and (h) on Figure (2) show how average bid spread and discount change with volatility: average bid spread is positively, while average discount is negatively correlated with volatility. Therefore, the WZ's model for the uniform format predicts that bidders increase bid spread and decrease discount as the variance of the value of the good increases. Bid spread is equal to the high bid in the WZ's model, so that we conclude that average high bid increases with volatility. From panels (i) and (j), note that the WZ's model predicts that the standard deviation of bid spread, high bid and discount are positively correlated with volatility.

Figure (3) represent the empirical implications of both models for the uniform auction on average bidder's profit: both AM and WZ predict that average per unit bidders' profit increase with volatility.

For the discriminatory format in the AM's model, remember that bid spread is zero, since bidder bid the same price for both units. The Figures illustrating how the average and the standard deviation of discount and of the bid for both units, as well as the average bidders' profit vary with volatility have similar shapes to those presented for the uniform format, so that we present the Figures on Appendix C. We conclude that the AM's model for the discriminatory auction predicts that bidders decrease their bid increasing discount as volatility increases, and as a result bidders' per unit profit increases. Intra-auction heterogeneity on bids increase with volatility, while the behavior of discount is not monotonous.

We summarize these facts in Table (5). In the Table, the first two columns summarize the predictions from the AM's uniform and discriminatory auctions, $A M^{u}$ and $A M^{d}$, respectively, and the third column, from the $W Z$ uniform auction. A $\uparrow$ or a $\downarrow$ indicates that the corresponding variable is positively or negatively correlated with volatility. A $\curvearrowright$ indicates that the relation between the variable and volatility is not monotonous. Empty cells indicates that the model does not have an implication for that particular variable.

Note that both models predict an increase in average bid spread as volatility increases, but have different implications for average high bid and average discount. The differences can be understand if we consider how the equilibria change in both models for the uniform auction with volatility. Figure (4) illustrate the change, on the left for the AM and on the right for the WZ's uniform auction. In the AM's model, as volatility increases, for a given signal, bidders decrease both their high and low bid, increasing bid spread. As a result, discount increases. In the WZ's model, on the other hand, as volatility

\footnotetext{
data.

${ }^{24} \mathrm{We}$ vary $\sigma_{\varepsilon}^{2}$ in order to check the robustness of the analysis to a parameter whose value is not directly related to the
} 


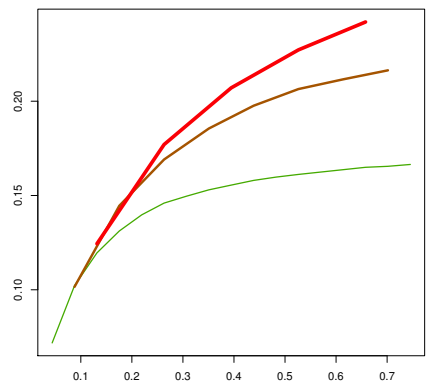

(a) $A M^{u}$ Avg Bid Spread

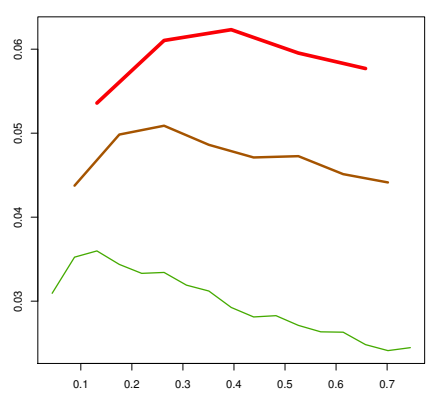

(d) $A M^{u}$ Std Bid Spread

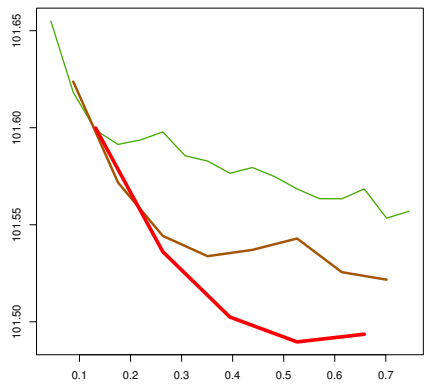

(b) $A M^{u}$ Avg High Bid

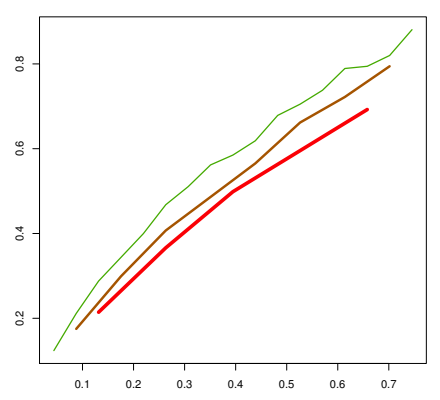

(e) $A M^{u}$ Std High Bid

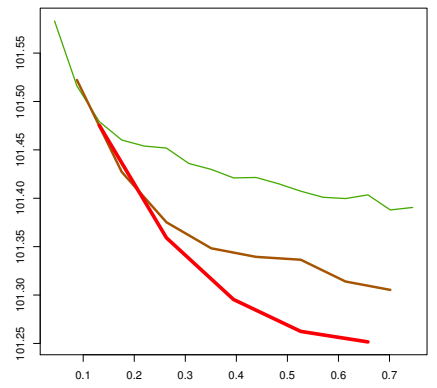

(c) $A M^{u}$ Avg Low Bid

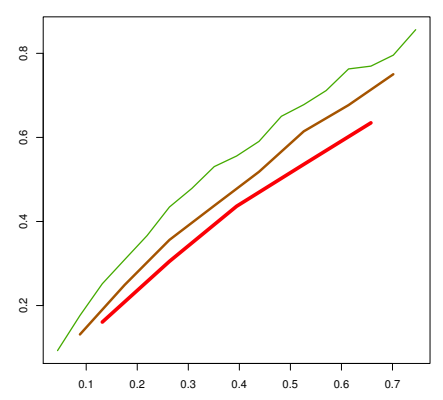

(f) $A M^{u}$ Std Low Bid

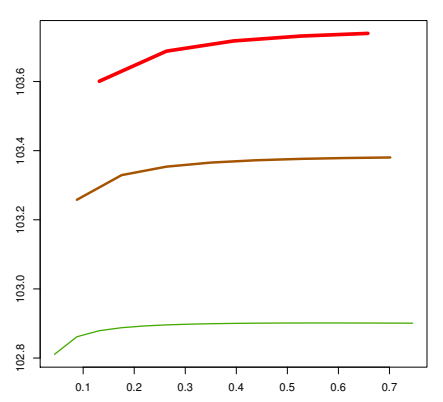

(g) WZ Avg Bid Spread

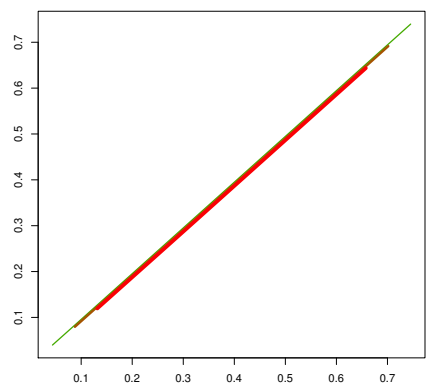

(i) WZ Std Bid Spread

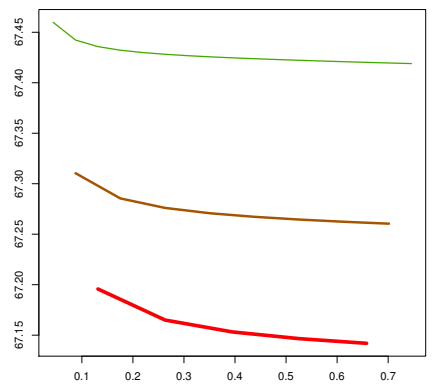

(h) WZ Avg Discount

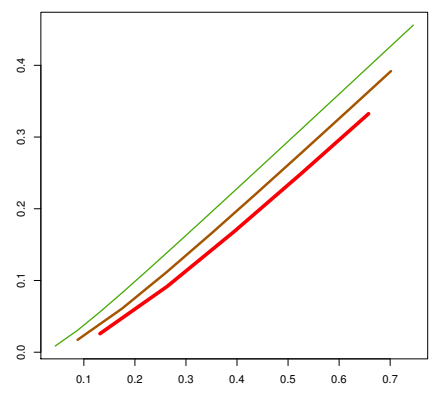

(j) WZ Std Discount

Fig. 2: Bidding behavior and volatility for the AM and WZ's uniform auction 


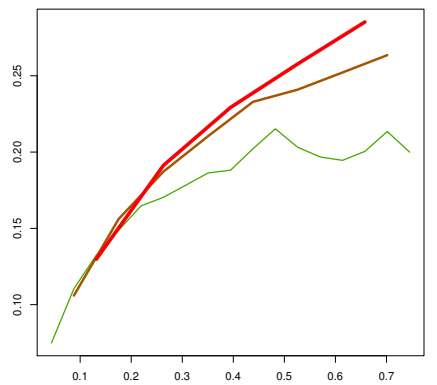

(a) $A M^{u}$ Avg Profit

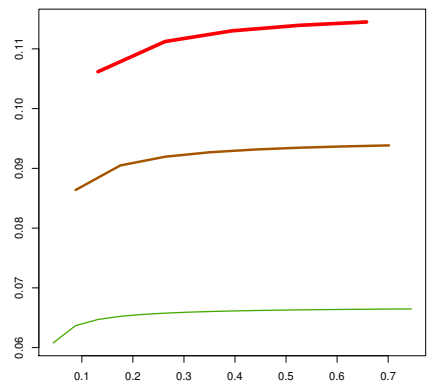

(b) WZ Avg Profit

Fig. 3: Bidders' profit per unit and volatility for the AM and WZ's uniform auction

Table 5: Theoretical implications: A $\uparrow$ or a $\downarrow$ indicates that the corresponding variable is positively or negatively correlated with volatility. A $\curvearrowright$ indicates that the relation between the variable and volatility is not monotonous. Empty cells indicates that the model does not have an implication for that particular variable.

\begin{tabular}{|c|c|ccc|}
\hline & & $A M^{u}$ & $A M^{d}$ & WZ \\
\hline \hline \multirow{5}{*}{ Avg } & Bid Spread & $\uparrow$ & & $\uparrow$ \\
& High Bid & $\downarrow$ & & $\uparrow$ \\
& Low Bid & $\downarrow$ & & \\
& Discount & $\uparrow$ & $\uparrow$ & $\downarrow$ \\
& Profit & $\uparrow$ & $\uparrow$ & $\uparrow$ \\
\hline \hline \multirow{5}{*}{ Std } & Bid Spread & $\curvearrowright$ & & $\uparrow$ \\
& High Bid & $\uparrow$ & & $\uparrow$ \\
& Low Bid & $\uparrow$ & & \\
& Discount & $\curvearrowright$ & $\curvearrowright$ & $\uparrow$ \\
& Profit & & & \\
& & & & \\
\hline
\end{tabular}

increases, for a given signal, bidders rotate clockwise their demand: they bid higher for the first units, but decrease total quantity demanded and the price bid for the last units, increasing bid spread, in such a way that they increase the weighted average price of their demand. ${ }^{25}$ That is why discount decreases with volatility in the WZ's model. ${ }^{26}$

Both models imply that, on average, bidders' profit per unit increases with volatility. In the AM's model, since bidders lower their bids both for the uniform and discriminatory auction as volatility increases. In the WZ's model, because bidders decrease total quantity demanded and lower the price bid for units that could be pivotal determining the stop-out price.

\footnotetext{
${ }^{25}$ It can be shown analytically that the weighted average price is one third of the demand intercept.

${ }^{26}$ Note that for the WZ's model, there is a family of parallel demands for different signal observations, that shifts clockwise as volatility increases. Additionally, since there is a mean preserving spread on the distribution of the value of the good and therefore on the distribution of signals as volatility increases, the range of possible demand intercepts increases with volatility.
} 


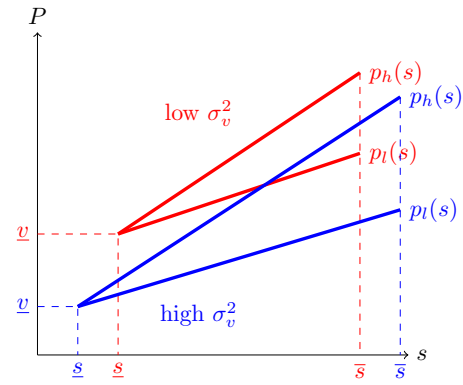

(a) $A M^{U}$ 's model

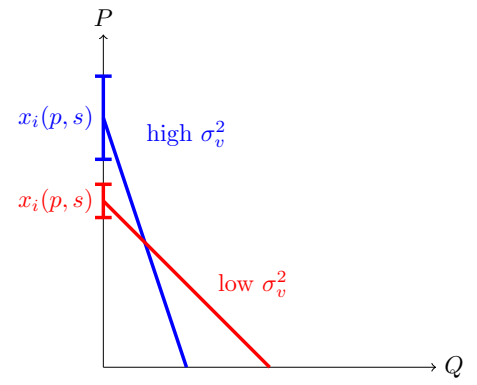

(b) WZ's model

Fig. 4: Effect of changing volatility in equilibrium strategies for the AM's uniform auction (on the left) and the WZ's uniform auction

\section{Empirical Analysis of Bidders' Behavior and Auction Results}

In this Section we check if the observed bidders' behavior and auction results are consistent with the empirical implications derived from the models presented in Subsection 4.3. We regress the average and the standard deviation of the defined variables in each auction on volatility. Since bidders' behavior could vary depending on bond type, we also include as regressors dummy variables for bond type, excluding 10 year bonds. All regressions are ordinary least squares, and the tables present the estimated coefficient, with the standard errors in parenthesis. In the Tables, $(*),(* *)$ and $(* * *)$ indicates that the corresponding coefficient is significant with a p-value lower than $0.1,0.05$ or 0.01 , respectively. The variables defining bidding behavior and auction results are as defined on Section 3.

Table (6) reports regressions of average bid spread, high and low bid as the dependent variables. Bid spread is significantly correlated with volatility with a p-value of 0.25 . As both models for the uniform auction predict, average bid spread increases with volatility: bidders respond to higher uncertainty about the value of the good increasing the difference between their high and their low bid. Gordy (1999) also finds that bidders increase bid spread as volatility increases, in Portuguese discriminatory bill auctions. Average high and low bid are not significantly correlated with volatility. Note that there is high volatility both with high and low yields, that are inversely correlated with prices. So, even if volatility has an effect on the level of price bids, the estimated coefficients are capturing both the effect on price levels and on volatility. Both for average high and low bids, dummy variables for bond type with maturity above 10 years are significant at the standard significance levels, since prices and therefore high and low bids are increasing with bond maturity.

Table (7) reports regressions of average discount and bidder's profit per unit as the dependent variables. As the AM's model implies, average discount is positively and significantly correlated with volatility, suggesting that bidders increase bid shading as the secondary market volatility increases. This result on discount is similar to Keloharju et al (2005), Nyborg et al (2002), Rocholl (2006), and Cammack (1991), among others, that also find a positive and significant correlation between discount and volatility. Additionally, as both models imply, average bidders' profit is also positively and significantly correlated with volatility. Note that dummy variables for bond type are significant, ${ }^{27}$ and that per unit profit decreases with bond maturity.

Table (8) reports regressions of the standard deviation of bid spread, high and low bid as dependent variables. As both models predict, the standard deviation of the high bid increases with volatility. The standard deviation of low bid, the coefficient of volatility is positive with a p-value of 0.12, as the AM's model predicts. However, the standard deviation of bid spread is not correlated with volatility, as the models predict. As volatility increases, the heterogeneity of high and low bid increases, while keeping the heterogeneity of bid spread constant.

Finally, (9) reports regressions of the standard deviation of discount and profit as dependent variables. As the WZ's model implies, the standard deviation of discount is positively and significantly correlated

${ }^{27}$ With a p-value equal to 0.1 for Dummy B30. 
Table 6: Bidding behavior, auction results and volatility I (averages)

\begin{tabular}{|c|c|c|c|}
\hline & \multicolumn{3}{|c|}{ Dependent variable: } \\
\hline & $\begin{array}{c}\text { Average Bid Spread } \\
(1) \\
\end{array}$ & $\begin{array}{l}\text { Average High Bid } \\
\qquad(2)\end{array}$ & $\begin{array}{c}\text { Average Low Bid } \\
(3) \\
\end{array}$ \\
\hline Volatility & $\begin{array}{c}0.142 \\
(0.122)\end{array}$ & $\begin{array}{c}-4.771 \\
(8.171)\end{array}$ & $\begin{array}{c}-4.913 \\
(8.145)\end{array}$ \\
\hline Dummy B3 & $\begin{array}{c}-0.013 \\
(0.029)\end{array}$ & $\begin{array}{c}-2.153 \\
(1.913)\end{array}$ & $\begin{array}{c}-2.140 \\
(1.907)\end{array}$ \\
\hline Dummy B5 & $\begin{array}{r}-0.041^{*} \\
(0.023)\end{array}$ & $\begin{array}{c}-0.812 \\
(1.559)\end{array}$ & $\begin{array}{c}-0.771 \\
(1.554)\end{array}$ \\
\hline Dummy B15 & $\begin{array}{c}-0.023 \\
(0.028)\end{array}$ & $\begin{array}{l}10.381^{* * *} \\
(1.859)\end{array}$ & $\begin{array}{l}10.404^{* * *} \\
(1.854)\end{array}$ \\
\hline Dummy B30 & $\begin{array}{c}0.002 \\
(0.048)\end{array}$ & $\begin{array}{l}10.432^{* * *} \\
(3.211)\end{array}$ & $\begin{array}{l}10.430^{* * *} \\
(3.201)\end{array}$ \\
\hline Constant & $\begin{array}{c}0.051 \\
(0.035)\end{array}$ & $\begin{array}{c}103.008^{* * *} \\
(2.310)\end{array}$ & $\begin{array}{c}102.957^{* * *} \\
(2.303)\end{array}$ \\
\hline Observations & 88 & 88 & 88 \\
\hline $\mathrm{R}^{2}$ & 0.252 & 0.524 & 0.523 \\
\hline Adjusted $\mathrm{R}^{2}$ & 0.207 & 0.495 & 0.494 \\
\hline Residual Std. Error $(\mathrm{df}=82)$ & 0.063 & 4.242 & 4.229 \\
\hline F Statistic $(\mathrm{df}=5 ; 82)$ & $5.533^{* * *}$ & $18.046^{* * *}$ & $17.960^{* * *}$ \\
\hline
\end{tabular}

with volatility. As volatility increases, the dispersion of discount among bidders in a given auction increases. Note that the AM's model also implies a positive correlation between discount and volatility for low values of $\sigma_{v}^{2}$. From panel (b) of Figure (5) in Appendix B, given that low volatility values are more frequent than high ones in our sample, we conclude that the empirical findings for the standard deviation of discount are also on line with the implications of AM's model. From the regression of the standard deviation of profit, note that dummy variables are significant and show how the dispersion of per unit profit increases with bond maturity. ${ }^{28}$

For all the variables for which volatility is significant on the regressions, Appendix D present scatter plots of volatility versus the corresponding variable, as well as a plot and ACF of residuals, showing no evidence of autocorrelation.

We summarize the empirical results on Table (10), and compare them with the empirical implications from the models. Table (10) adds to Table (5) a column to the right with the empirical results. A $\uparrow$ indicates that the estimated volatility coefficient is positive and significant; $\left({ }^{*}\right),\left({ }^{* *}\right)$ and $\left({ }^{* *}\right)$ indicates that the coefficient is significant with a p-value lower than $0.1,0.05$ or 0.01 , respectively, and a number in parenthesis shows the p-values if it is greater than 0.1. An empty cell indicates non significantly different from zero estimates. Shadowed cells indicates that the empirical results agree with the theoretical predictions.

\footnotetext{
${ }^{28} \mathrm{We}$ do not report regressions of the mean and standard deviation of the number of bids per bidder in an auction; neither of them is significantly correlated with volatility.
} 
Table 7: Bidding behavior, auction results and volatility II (averages)

\begin{tabular}{|c|c|c|}
\hline & \multicolumn{2}{|c|}{ Dependent variable: } \\
\hline & $\begin{array}{c}\text { Average Discount } \\
(1)\end{array}$ & $\begin{array}{c}\text { Average Profit } \\
(2) \\
\end{array}$ \\
\hline Volatility & $\begin{array}{l}0.307^{* *} \\
(0.120)\end{array}$ & $\begin{array}{l}2.096^{* * *} \\
(0.630)\end{array}$ \\
\hline Dummy B3 & $\begin{array}{c}0.035 \\
(0.030)\end{array}$ & $\begin{array}{l}0.395^{* * *} \\
(0.148)\end{array}$ \\
\hline Dummy B5 & $\begin{array}{c}0.009 \\
(0.024)\end{array}$ & $\begin{array}{l}0.267^{* *} \\
(0.121)\end{array}$ \\
\hline Dummy B15 & $\begin{array}{c}0.058^{*} \\
(0.031)\end{array}$ & $\begin{array}{r}-0.269^{*} \\
(0.140)\end{array}$ \\
\hline Dummy B30 & $\begin{array}{c}0.018 \\
(0.048)\end{array}$ & $\begin{array}{r}-0.411 \\
(0.249)\end{array}$ \\
\hline Constant & $\begin{array}{r}-0.069^{*} \\
(0.035)\end{array}$ & $\begin{array}{c}-0.590^{* * *} \\
(0.178)\end{array}$ \\
\hline Observations & 60 & 79 \\
\hline $\mathrm{R}^{2}$ & 0.548 & 0.226 \\
\hline Adjusted $\mathrm{R}^{2}$ & 0.506 & 0.173 \\
\hline Residual Std. Error & $0.055(\mathrm{df}=54)$ & $0.313(\mathrm{df}=73)$ \\
\hline F Statistic & $13.095^{* * *}(\mathrm{df}=5 ; 54)$ & $4.265^{* * *}(\mathrm{df}=5 ; 73)$ \\
\hline
\end{tabular}

Table (10) shows that AM's model delivers the right comparative statics for all variables that are significantly correlated with volatility, except for the standard deviation of discount. ${ }^{29}$ Moreover, the WZ's model also delivers the right comparative statics for all variables that are significantly correlated with volatility, except for average discount. Note that the WZ's model is only for the uniform auction, and has the limitation that demand schedules are linear and with a slope that do not depend on the signal, what could explain the failure to deliver the right comparative statics for average discount.

\subsection{Robustness checks}

The empirical results that we have presented are robust to other specifications. First, we have explored the effect of including duration as an additional regressor. ${ }^{30}$ Second, since volatility and duration have a correlation coefficient of 0.96 , we orthogonalized the volatility measure, regressing volatility on duration, and included the estimated residuals, orthogonalized volatility, as a regressor, instead of volatility. In

${ }^{29}$ Although the model implies correctly that the standard deviation of discount and volatility are positively correlated for low values of volatility.

${ }^{30}$ The duration of a financial asset that consists of fixed cash flows, as a bond, is the weighted average of the times until those fixed cash flows are received, with the weights proportional to the present value of the payment. It is a measurement of how long, in years, it takes for the price of a bond to be repaid by its internal cash flows. Duration is defined as

$$
D=\frac{1}{P} \sum_{t=1}^{T} t \frac{C F_{t}}{(1+r)^{t}}
$$

where $T$ is the number of cash flows, $C F_{t}$ is the cash flow at time $t, t$ is the time in years until the payment will be received, $r$ is the internal rate of return, and $P$ is the bond price. The internal rate of return, $r$, is the rate that makes the net present value of all cash flows equal to zero. In other words, it is the rate at which an investment breaks even. 
Table 8: Bidding behavior, auction results and volatility III (standard deviations)

\begin{tabular}{|c|c|c|c|}
\hline & \multicolumn{3}{|c|}{ Dependent variable: } \\
\hline & $\begin{array}{c}\text { Std. Dev. Bid Spread } \\
\text { (1) }\end{array}$ & $\begin{array}{c}\text { Std. Dev. High Bid } \\
(2)\end{array}$ & $\begin{array}{c}\text { Std. Dev. Low Bid } \\
(3)\end{array}$ \\
\hline Volatility & $\begin{array}{c}0.208 \\
(0.435)\end{array}$ & $\begin{array}{l}0.443^{* *} \\
(0.212)\end{array}$ & $\begin{array}{c}0.600 \\
(0.380)\end{array}$ \\
\hline Dummy B3 & $\begin{array}{r}-0.043 \\
(0.102)\end{array}$ & $\begin{array}{c}0.071 \\
(0.050)\end{array}$ & $\begin{array}{c}0.011 \\
(0.089)\end{array}$ \\
\hline Dummy B5 & $\begin{array}{r}-0.134 \\
(0.083)\end{array}$ & $\begin{array}{c}0.022 \\
(0.041)\end{array}$ & $\begin{array}{r}-0.046 \\
(0.073)\end{array}$ \\
\hline Dummy B15 & $\begin{array}{r}-0.058 \\
(0.099)\end{array}$ & $\begin{array}{r}-0.050 \\
(0.048)\end{array}$ & $\begin{array}{r}-0.076 \\
(0.087)\end{array}$ \\
\hline Dummy B30 & $\begin{array}{r}-0.073 \\
(0.171)\end{array}$ & $\begin{array}{r}-0.141^{*} \\
(0.083)\end{array}$ & $\begin{array}{r}-0.164 \\
(0.150)\end{array}$ \\
\hline Constant & $\begin{array}{c}0.138 \\
(0.123)\end{array}$ & $\begin{array}{r}-0.037 \\
(0.060)\end{array}$ & $\begin{array}{c}0.016 \\
(0.108)\end{array}$ \\
\hline Observations & 88 & 88 & 88 \\
\hline $\mathrm{R}^{2}$ & 0.070 & 0.060 & 0.109 \\
\hline Adjusted $\mathrm{R}^{2}$ & 0.014 & 0.002 & 0.054 \\
\hline Residual Std. Error $(\mathrm{df}=82)$ & 0.226 & 0.110 & 0.197 \\
\hline F Statistic $(\mathrm{df}=5 ; 82)$ & 1.242 & 1.040 & $1.996^{*}$ \\
\hline
\end{tabular}

Note:

${ }^{*} \mathrm{p}<0.1 ;{ }^{* *} \mathrm{p}<0.05 ;{ }^{* * *} \mathrm{p}<0.01$

both cases, results on the sign and significativity of volatility do not change with respect to the results presented above. We also restricted the sample only to reopenings; there are only 6 auctions for new securities, and the results do not change.

We have considered alternative measures for two variables, volatility and bid spread. For volatility we have tried two alternatives. First, we have considered a k-day window preceding the auction, and have calculated the variance of the trading prices in that window, for $\mathrm{k}$ from 5 to 20. However, the obtained series have very low variation and are not significant on the regressions. Second, we have considered the bid-ask spread of the auctioned bonds. The problem is that we have that information only for bonds auctioned from January 2005 to December 2007. For the bonds for which we have both volatility measures, we reject the null hypothesis of no correlation against the alternative of positive correlation, at the standard significance levels, using non parametric measures of statistical dependence. We use both Spearman's and Kendall's rank correlation tests. Results are presented on Table (12) on Appendix B. Therefore, we expect similar results with both volatility measures. For bid spread we also considered an alternative measure, weighted bid spread. We calculate the median of quantity demanded, and define weighted high bid as the quantity weighted price of bids above the median; weighted low bid is defined in a similar way, and weighted average bid spread is the difference between weighted high and low bid. Regression analysis with weighted average bid spread as dependent variable are similar to the ones using bid spread.

\section{Conclusions}

In this paper we present evidence that bidders' behavior in Spanish Treasury auctions follows the predictions of two theoretical common value models with private information, using a sample of 88 Spanish 
Table 9: Bidding behavior, auction results and volatility IV (standard deviations)

\begin{tabular}{lcc}
\hline \hline & \multicolumn{2}{c}{ Dependent variable: } \\
\cline { 2 - 3 } & Std. Dev. Discount & Std. Dev. Profit \\
& $(1)$ & $(2)$ \\
\hline Volatility & $0.511^{* * *}$ & -0.011 \\
& & $(0.014)$ \\
Dummy B3 & $0.074^{* * *}$ & $-0.009^{* * *}$ \\
& $(0.025)$ & $(0.003)$ \\
Dummy B5 & & \\
& $0.063^{* * *}$ & $-0.006^{* *}$ \\
Dummy B15 & $(0.020)$ & $(0.003)$ \\
& & \\
Dummy B30 & $(0.026)$ & $0.007^{* *}$ \\
& & $(0.003)$ \\
Constant & $-0.099^{* *}$ & $0.019^{* * *}$ \\
& $(0.041)$ & $(0.006)$ \\
& & \\
& $-0.083^{* * *}$ & $\left(0.016^{* * *}\right.$ \\
Observations & $(0.029)$ & 79 \\
$\mathrm{R}^{2}$ & & 0.538 \\
Adjusted $\mathrm{R}^{2}$ & 60 & 0.507 \\
Residual Std. Error & $0.046(\mathrm{df}=54)$ & $0.007(\mathrm{df}=73)$ \\
F Statistic & $11.327^{* * *}(\mathrm{df}=5 ; 54)$ & $17.033^{* * *}(\mathrm{df}=5 ; 73)$ \\
\hline \hline Note: & & ${ }^{*} \mathrm{p}<0.1 ;{ }^{* *} \mathrm{p}<0.05 ;{ }^{* * *} \mathrm{p}<0.01$ \\
& &
\end{tabular}

Treasury bond auctions, held between 2003 and 2007. We find that, on average, bidders respond to an increase in the volatility of prices in the secondary market increasing discount, which implies an increase in bidders' profit per unit.

The novelty of the paper is the focus on intra-auction heterogeneity in Treasury Bond auctions: how and why bidders bid differently from each other within an auction.

Our first conclusion is that intra-auction heterogeneity, as compared to inter-auction heterogeneity, is relevant for some variables summarizing bidding behavior, particularly bid spread and discount. Secondly, we find that intra-auction heterogeneity can be partially explained by the volatility of prices in the secondary market for the bond being auctioned.

We have analyzed to what extent the correlation between intra-auction heterogeneity and secondary market volatility can be explained within the existing theoretical models of multi-unit multi-bid auctions. To obtain empirical implications, we consider common values models with private information providing an explicit expression for the equilibrium strategies. First, we use common value models with private information to obtain empirical implications for the intra-auction heterogeneity observed in our data. Second, we use models with an explicit expression of the equilibrium strategies because they allow to easily simulate bids as a function of sample statistics, including secondary market volatility. 
Table 10: Empirical Implications versus Empirical results. This Table adds to Table (5) a column to the right summarizing the empirical results. In that column, a $\uparrow$ indicates that the estimated volatility coefficient is positive and significant; $(*)$, $(* *)$ and $(* * *)$ indicates that the coefficient is significant with a p-value lower than $0.1,0.05$ or 0.01 , respectively, and a number in parenthesis shows the p-values if it is greater than 0.1. An empty cell indicates non significantly different from zero estimates (with p-values much larger than the largest shown in the table). Shadowed cells indicates that the empirical results agree with the theoretical predictions.

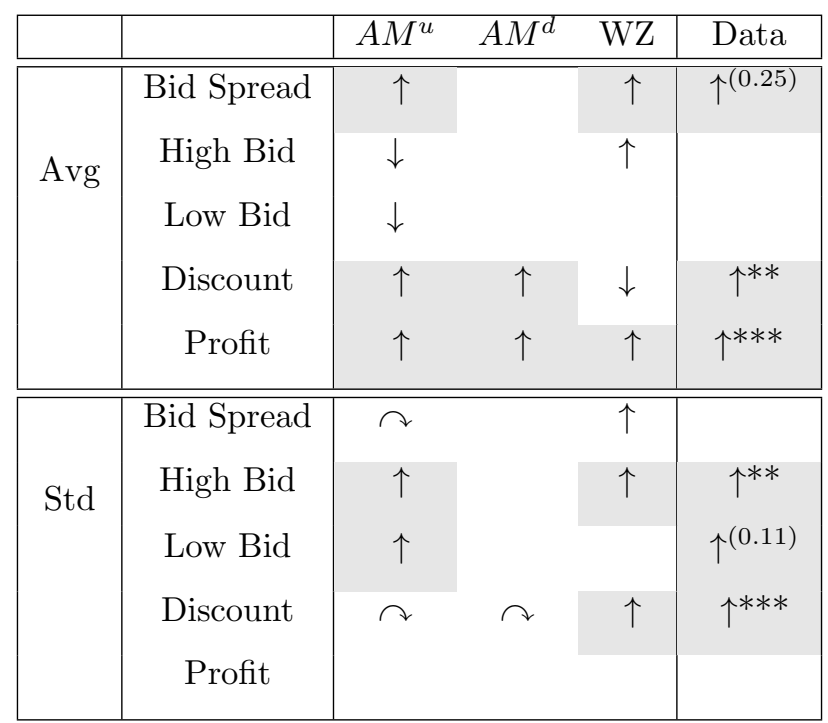

\section{A Institutional background: Additional details}

\section{A.1 Auctions}

The Spanish Treasury issues Bonos y Obligaciones del Estado, Treasury bonds, securities with maturities above two years, paying annual coupons. Maturities for Bonos are three and five years, while Obligaciones have maturities of 10,15 and 30 years. ${ }^{31}$ Bids must be made for at least 1,000 Euros or a multiple of this minimum amount, and are either competitive, specifying both the quantity desired and the price, or non-competitive, specifying only the quantity desired. Non-competitive bids are accepted in full and pay the auction's weighted average price. There is a maximum of 1,000,000 Euros on noncompetitive bids submitted by each participant. Any investor can submit bids in the auctions, although most bids are made by Market Makers, a group of financial institutions with given obligations and rights, whose purpose is to stimulate the liquidity of the secondary market in Public Debt and co-operate in the diffusion of Government Debt domestically and abroad. To qualify as a Market Maker, institutions must apply to the Treasury and fulfill some requirements, that include presenting at each auction requests for a minimal nominal value of 3 per cent of the amount sold by the Treasury for each type of instrument, at prices not less than the stop-out price, less a given amount, that depends on the maturity. Additionally, they have to guarantee the liquidity of the secondary market, with listing obligations. As a compensation, they may present requests on the day of the auction until the time of the auction. They also have exclusive access to the second rounds, carried out between the resolution of the auction and the twelve hours of the working day before the issue is put into circulation, and the top ranked are chosen to carry out debt management deals.

Over the period considered, the mean aggregate quantity demanded is 2,747 thousand millions of Euros, while the mean auction size is 1,334 thousand millions of Euros, with a mean cover ratio of 2.15.

\section{A.2 Secondary Markets}

Secondary market trades for Spanish government debt are conducted through three systems, two of them, the first and second tier, reserved for market members or account holders, and the third for transactions between market members and third parties. The first tier or blind market, is an electronic platform in which trades are electronically conducted without the knowledge of the counter party identity. This is the core of the public debt market, as participating agents undertake to quote bid and ask prices at relatively narrow spreads (around 5 basis points in keenly traded issues), thereby guaranteeing the market's overall liquidity. Transaction size is a minimum of 5 million Euros. Blind market trades may only be to maturity, whether in spot or forward transactions.

${ }^{31}$ The Treasury also issues Letras del Tesoro, Treasury bills, short-term instruments, with 3 , 6 , 12 and 18 months maturity. In this paper we do not analyze Treasury bill auctions, since the secondary market for bills is very illiquid and there is not a reliable measure of secondary market volatility. 


\section{B Volatility Estimations: Additional Details}

The estimated $\mathrm{ARCH}(1)$ model is

$$
e_{t}^{2}=a_{0}+a_{1} e_{t-1}^{2}+v_{t}
$$

When there is no data for a bond in a given day, first we use a time series interpolation within a five day window, i.e., if there is data for that bond around the missing date, and no more than 5 days have elapsed, we use for the missing day the average of the two closest dates. If there are no data in that window, we use the price of the traded Treasury bond with duration that most closely mimics the duration of the new Treasury bond for the day in which the data is missing. When a new Treasury bond is auctioned, we use the average winning auction yield to compute duration.

Table (11) present estimates for the model for each ISIN code.

Table 11: Estimates of the ARCH(1) model. Each row is the estimate for an ISIN code. The first two columns present the estimated coefficients, and the third and fourth columns, the corresponding $t$ statistic. The fifth column presents the Box-Ljung statistic. The last column indicates the percentage of missing data on a daily basis for the corresponding ISIN code.

\begin{tabular}{|cccccc|}
\hline$\hat{a}_{0}$ & $\hat{a}_{1}$ & $t\left(\hat{a}_{0}\right)$ & $t\left(\hat{a}_{1}\right)$ & Box-Ljung & \% missing \\
\hline \hline 0.07 & 0.20 & 26.89 & 7.12 & 0.44 & 0.01 \\
0.01 & 0.28 & 18.63 & 5.55 & 0.22 & 0.02 \\
0.05 & 0.09 & 16.48 & 2.30 & 0.93 & 0.00 \\
0.00 & 0.35 & 19.18 & 5.04 & 0.41 & 0.02 \\
0.05 & 0.17 & 9.52 & 2.00 & 0.68 & 0.01 \\
0.03 & 0.20 & 9.40 & 2.14 & 0.95 & 0.11 \\
0.27 & 0.21 & 29.16 & 6.01 & 0.20 & 0.01 \\
0.11 & 0.15 & 41.53 & 4.99 & 0.59 & 0.01 \\
0.06 & 0.22 & 34.52 & 6.17 & 0.26 & 0.00 \\
0.01 & 0.87 & 30.55 & 14.85 & 0.11 & 0.00 \\
0.00 & 0.64 & 44.99 & 9.90 & 0.49 & 0.00 \\
0.05 & 0.22 & 26.78 & 6.76 & 0.25 & 0.00 \\
0.01 & 0.29 & 25.01 & 7.63 & 0.45 & 0.01 \\
0.00 & 0.56 & 24.81 & 8.84 & 0.32 & 0.01 \\
0.06 & 0.13 & 66.62 & 5.14 & 0.11 & 0.00 \\
0.48 & 0.09 & 106.31 & 4.33 & 0.33 & 0.05 \\
\hline
\end{tabular}

Panel (a) on Figure (5) shows the histogram for the values of volatility for all 10-year bonds in our sample. Panel (b) show the histogram for the values of volatility on auction days, the subsample that we use on the empirical regressions. Finally, panel (c) plots an example for a specific bond; the vertical lines are auction days for that particular bond.

Table (12) presents rank correlation tests between CONT and BEST volatility time series. The null hypothesis (no correlation) is rejected against the alternative, positive correlation (greater) at the usual confidence interval.

Table 12: Non-parametric rank correlations among volatility measures

\begin{tabular}{rrrrr}
\hline method & statistic & p.value & estimate & alternative \\
\hline Spearman's rank correlation rho & 27624.000 & 0.000 & 0.757 & greater \\
Kendall's rank correlation tau & 7.756 & 0.000 & 0.562 & greater \\
\hline
\end{tabular}

\section{Empirical Implications from the AM Discriminatory Auction}

\section{Scatter plots, residuals and ACF's}

Figures (7), (8) and (11) present scatter plots of volatility versus the corresponding variable, and a plot and ACF of residuals, on panels (a), (b) and (c), respectively, for the variables for with volatility is significant on the empirical regressions. On panel (a) the scatter plot represent volatility on the horizontal axis and the corresponding variable on the vertical axis. The colors represent different bond types, with maturity increasing as the color shifts from green to red. Note that volatility and maturity are positively correlated: green points are to the left whereas red points are to right. The regression line illustrates a positive correlation between the variables. Panels (b) and (c) show no evidence of autocorrelation for the 

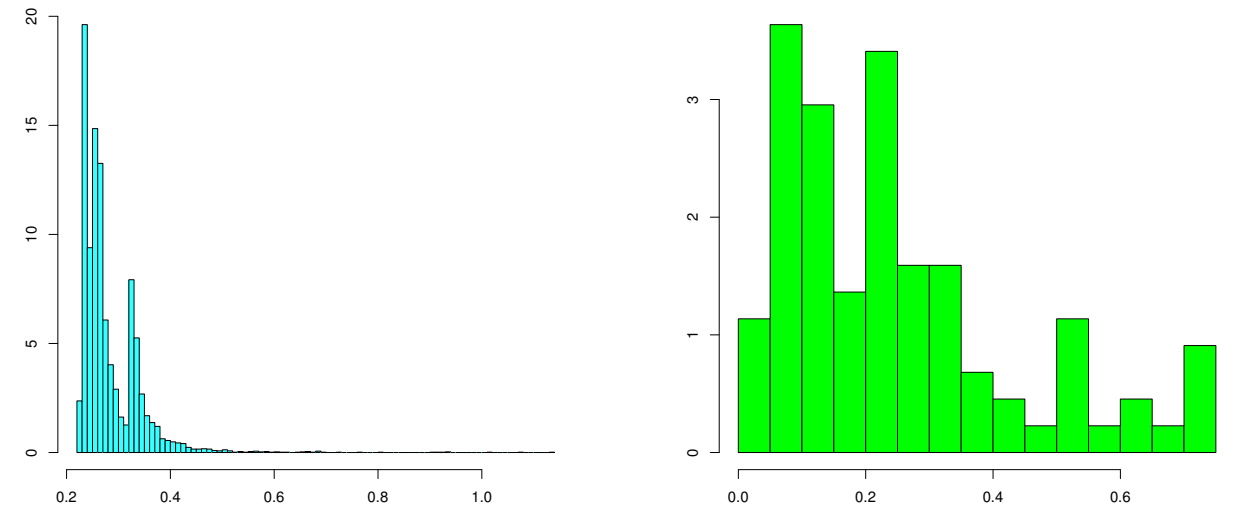

(a) Histogram of estimated volatility for all 10-year (b) Histogram of estimated volatility on auction bonds days

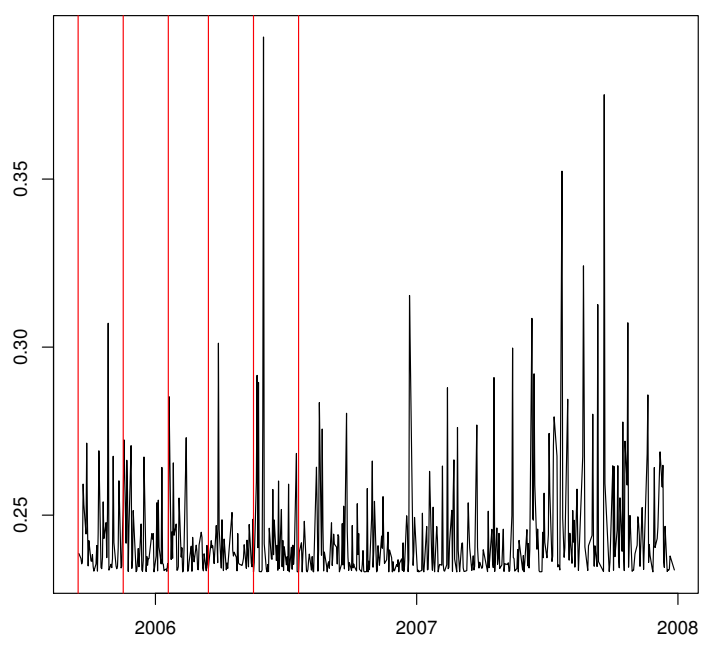

(c) An example of an estimated volatility time series. The bond code is ES00000120G4, a 10 year bond. The vertical lines are auction days for this bond.

Fig. 5: Histograms of volatility and an example of a time series for a 10-year bond

residuals. 


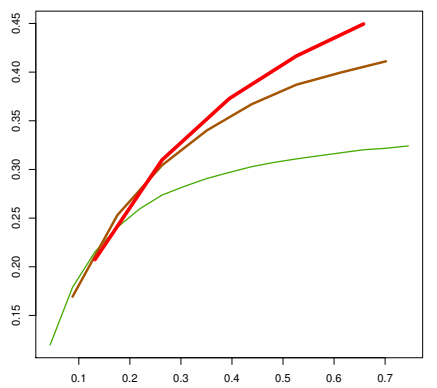

(a) $A M^{d}$ Avg Discount

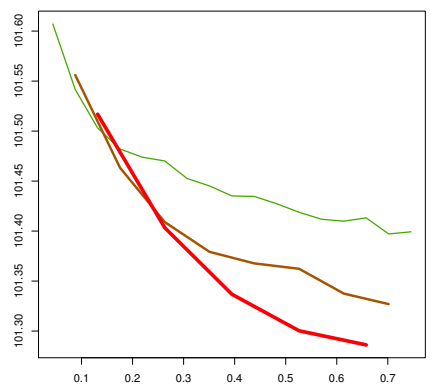

(b) $A M^{d}$ Avg Bid

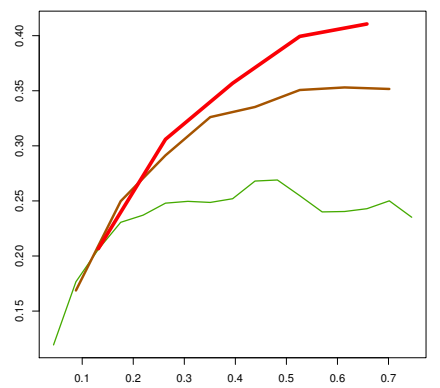

(c) $A M^{d}$ Avg Profit

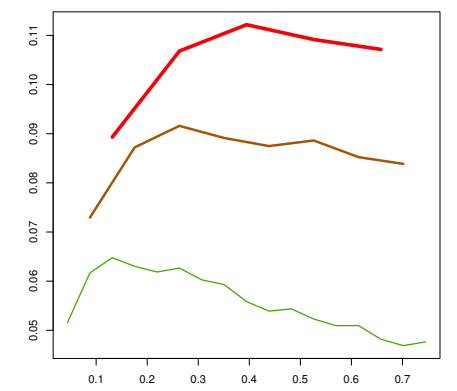

(d) $A M^{d}$ Std Discount

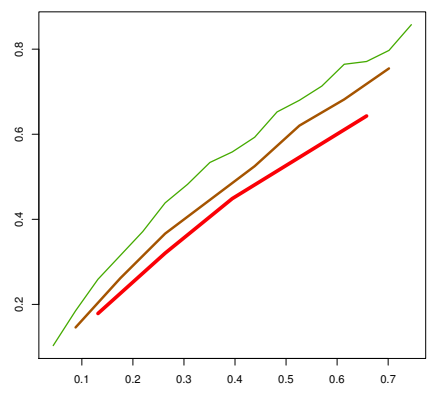

(e) $A M^{d}$ Std Bid

Fig. 6: Bid behavior, bidders' profit and volatility for the $A M^{d}$ 's model

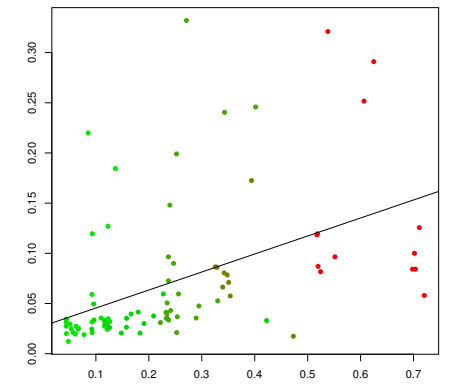

(a) Avg Bid Spread vs. Volatility

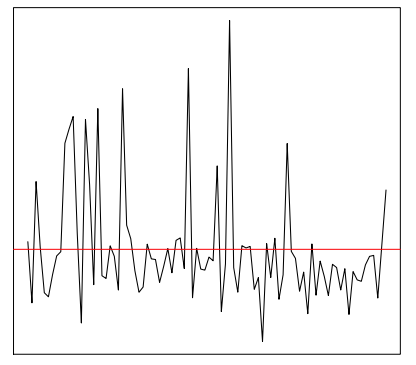

(b) Residuals

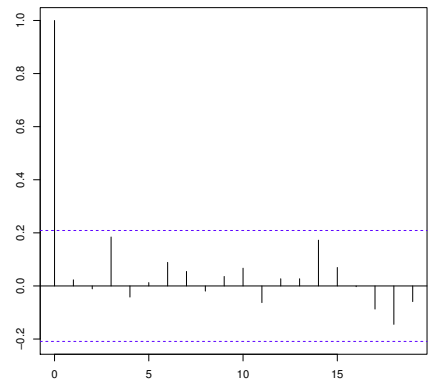

(c) $\mathrm{ACF}$

Fig. 7: Average bid spread 


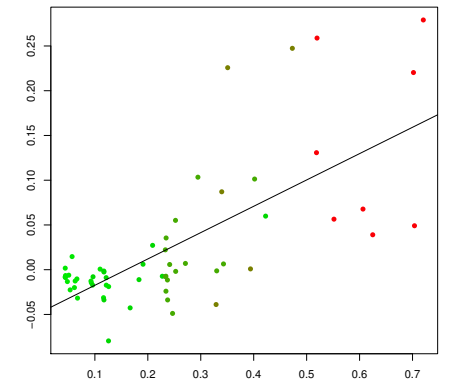

(a) Avg Discount vs. Volatility

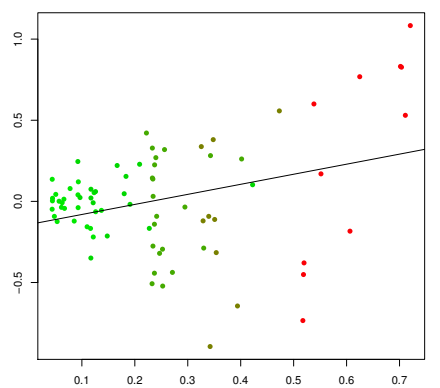

(a) Avg Profit vs. Volatility

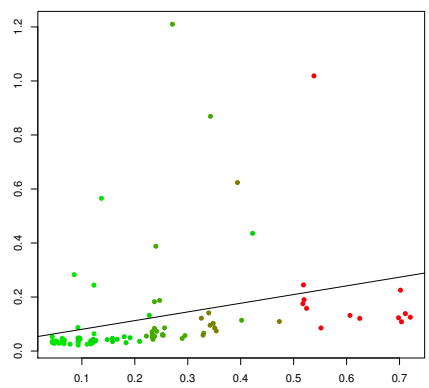

(a) Std Low Bid vs. Volatility

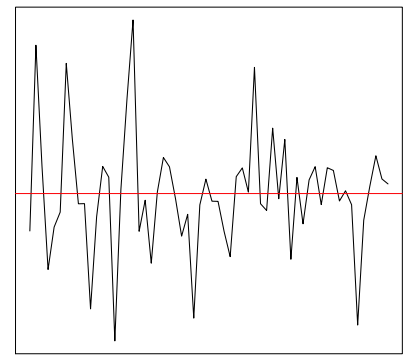

(b) Residuals

Fig. 8: Average discount

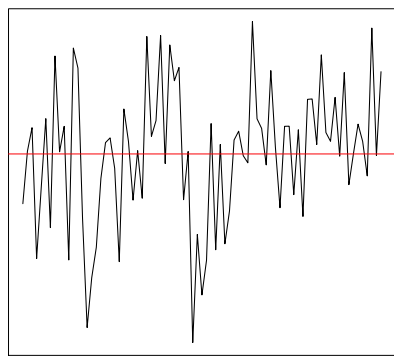

(b) Residuals

Fig. 9: Average profit

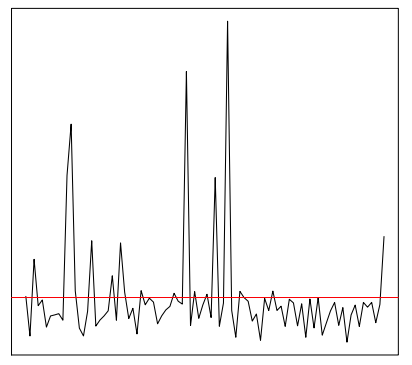

(b) Residuals

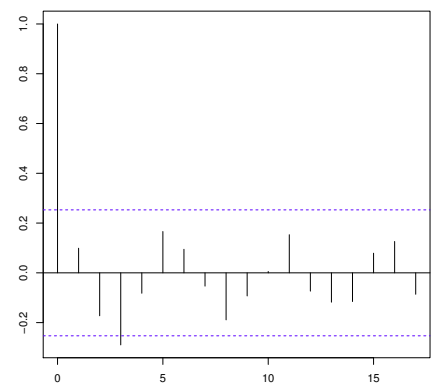

(c) $\mathrm{ACF}$

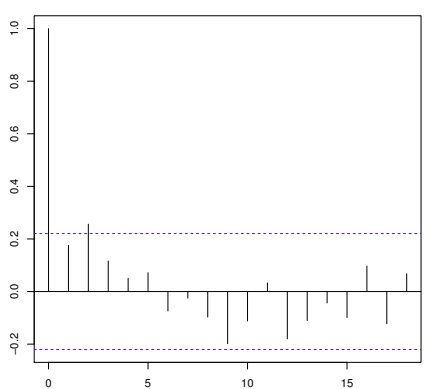

(c) $\mathrm{ACF}$

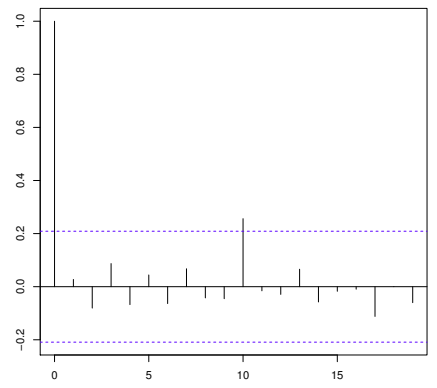

(c) $\mathrm{ACF}$

Fig. 10: Standard deviation of low bid 


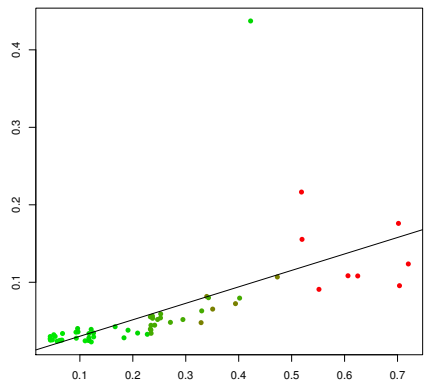

(a) Std Discount vs. Volatility

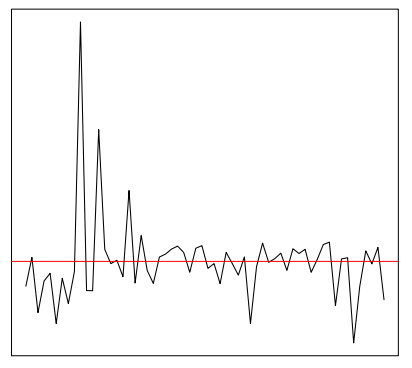

(b) Residuals

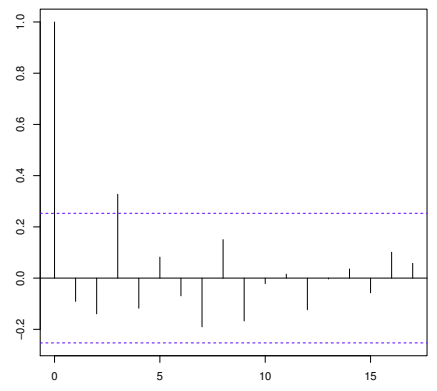

(c) $\mathrm{ACF}$

Fig. 11: Standard deviation of discount 
Acknowledgements We thank Soledad Nuñez and Enrique Martín Quilis from Secretaría General del Tesoro, for providing the auction data and for insightful conversations, Antonio Díaz for helping us with financial questions, Barry Readman for the linguistic revision of the text, and specially two anonymous referees for many valuable comments and suggestions. Any remaining error is our responsibility. We thank the financial support from Ministerio de Educación y Ciencia, grant SEJ2007-65722.

\section{References}

Alvarez F, Mazón C (2007) Comparing the spanish and the discriminatory auction formats: A discrete model with private information. European Journal of Operational Research 179(1):253 - 266, DOI 10.1016/j.ejor.2006.02.044, URL http: //www.sciencedirect.com/science/article/pii/S0377221706002505

Alvarez F, Mazón C (2012) Multi-unit auctions with private information: an indivisible unit continuous price model. Economic Theory 51(1):35-70, DOI 10.1007/s00199-010-0594-2, URL http://dx.doi.org/10.1007/s00199-010-0594-2

Armantier O, Lafhel N (2009) Comparison of auction formats in canadian government auctions. Tech. rep., Bank of Canada Working Paper

Armantier O, Sbaï E (2006) Estimation and comparison of treasury auction formats when bidders are asymmetric. Journal of Applied Econometrics 21(6):745-779, DOI 10.1002/jae.875, URL http://dx.doi.org/10.1002/jae.875

Arnone M, Iden G (2003) Primary Dealers in Government Securities: Policy Issues and Selected Countries Experience (EPub). International Monetary Fund

Cammack EB (1991) Evidence on bidding strategies and the information in treasury bill auctions. Journal of Political Economy pp 100-130

Dunne PG, Moore M, Portes R (2010) European government bond markets: Transparency, liquidity, efficiency. Tech. rep., CEPR Research Report

Elsinger H, Zulehner C (2007) Bidding behavior in austrian treasury bond auctions. Monetary Policy and the Economy Q 2:109-125

Fevrier PRP, Visser M (2002) Econometrics of Share Auctions. Working Papers 2002-09, Centre de Recherche en Economie et Statistique, URL http://ideas.repec.org/p/crs/wpaper/2002-09.html

Goldreich D (2007) Underpricing in discriminatory and uniform-price treasury auctions. Journal of Financial and Quantitative Analysis 42:443-466, DOI 10.1017/S0022109000003343, URL http://journals.cambridge.org/article_ S0022109000003343

Gordy MB (1999) Hedging winner's curse with multiple bids: Evidence from the portuguese treasury bill auction. Review of Economics and Statistics pp 448-465

Hortaçsu A (2011) Recent progress in the empirical analysis of multi-unit auctions. International Journal of Industrial Organization 29(3):345-349

Hortaçsu A, McAdams D (2010) Mechanism choice and strategic bidding in divisible good auctions: an empirical analysis of the turkish treasury auction market. Journal of Political Economy 118(5):833-865

Hortaçsu A (2002) Bidding behavior in divisible good auctions: Theory and empirical evidence from turkish treasury auctions," working paper

Kang BS, Puller SL (2008) The effect of auction format on efficiency and revenue in divisible goods auctions: a test using korean treasury auctions. The Journal of Industrial Economics 56(2):290-332, DOI 10.1111/j.1467-6451.2008.00342.x, URL http://dx.doi.org/10.1111/j.1467-6451.2008.00342.x

Kastl J (2011) Discrete bids and empirical inference in divisible good auctions. The Review of Economic Studies 78(3):9741014

Keloharju M, Nyborg KG, Rydqvist K (2005) Strategic behavior and underpricing in uniform price auctions: Evidence from finnish treasury auctions. Journal of Finance 60(4):1865-1902, URL http://ideas.repec.org/a/bla/jfinan/ v60y2005i4p1865-1902.html

Nyborg KG, Rydqvist K, Sundaresan SM (2002) Bidder behavior in multiunit auctions: Evidence from swedish treasury auctions. Journal of Political Economy 110(2):394-424

Pacini R (2006) Auctioning government securities: The puzzle of overpricing. Economics 1:1-45

Rocholl J (2006) Discriminatory auctions with seller discretion: evidence from german treasury auctions. Tech. Rep. 15/2005, Deutsche Bundesbank, Kenan-Flagler Business School, University of North Carolina at Chapel Hill

Wang JJ, Zender JF (2002) Auctioning divisible goods. Economic Theory 19(4):673-705, DOI 10.1007/s001990100191, URL http://dx.doi.org/10.1007/s001990100191 